\title{
Radiation-Based Neuromodulation: Rationale and New Directions
}

\author{
Bret Schneider $^{1}$, D. John. Borchers, John R. Adler ${ }^{1}$ \\ 1. Department of Neurosurgery, Stanford University School of Medicine 2. \\ $\square$ Corresponding author: Bret Schneider, schn@stanford.edu \\ Disclosures can be found in Additional Information at the end of the article
}

\section{Abstract}

It has been asserted that relief of trigeminal nerve pain following irradiation results from axonal degeneration and neuronal death. However, there could be another explanation of the observed clinical phenomena: pain relief may result from altered neuronal function. It is argued that optimal treatment of trigeminal neuralgia with stereotactically-delivered radiation may be achieved by altering neuronal behavior without tissue destruction. Multiple lines of evidence demonstrate that radiation can focally alter neuronal physiology. These experimental and clinical observations are reviewed. Radiomodulation may offer a tool by which hypermetabolic foci may be down-regulated in order to restore homeostasis within a malfunctioning neural circuit and treat clinical symptoms of functional and behavioral disorders.

Categories: Neurology, Pain Management, Neurosurgery

Keywords: trigeminal neuralgia, radiation, neuromodulation, radiosurgery

\section{Introduction And Background}

\section{From radiosurgery to radiomodulation}

At its inception, radiosurgery was perceived by its inventor, Lars Leksell, to be primarily a minimally-invasive procedure for making destructive brain lesions in patients with functional disorders. Although neuro-oncologic applications of radiosurgery have come to dominate, numerous studies now demonstrate the efficacy of stereotactic radiosurgery in treating selected patients with movement, seizure and psychiatric disorders. Much as Leksell once envisioned, radiosurgery has evolved into an effective alternative to invasive techniques, such as radiofrequency ablation and other open neurosurgical techniques. However, recent clinical observations in patients undergoing rhizotomy for trigeminal neuralgia and epilepsy suggest that precisely targeted irradiation can alter local neuronal function without inducing a necrotic/apoptotic lesion. Based on this new understanding, we wish to now propose a broader conceptual framework for how sub-lethal radiation might alter neuronal function and be used in other clinical conditions. We postulate that the rapid and enduring effects of

Published 02/08/2010

C) Copyright 2010

Schneider et al. This is an open access article distributed under the terms of the Creative Commons Attribution License CC-BY 3.0., which permits unrestricted use, distribution, and reproduction in any medium, provided the original author and source are credited. stereotactically-delivered radiation to histologically normal tissue depending upon dose, may exert its therapeutic effects principally by altering neuronal membrane physiology.

\section{Review}

\section{Radiomodulation: A clinical phenomenon}

It has been asserted that relief of trigeminal nerve pain following irradiation results from axonal degeneration. Such conclusions are based, in part, upon animal studies using various radiation doses [1]. However, there is an alternative, perhaps more compelling explanation for 
the observed clinical phenomena: that the pain relief resulted from altered function of surviving neurons, and the degeneration and death of neurons is simply an unintended and unnecessary collateral damage.

Multiple lines of evidence show that radiosurgery can non-destructively alter focal neuronal physiology. Regis, et al. was the first to describe localized irradiation, delivered within defined parameters, as a form of neuromodulation [2]. Over the previous two decades, several researchers noted the disappearance of seizures following a variety of radiation treatments from brachytherapy [3] to radiosurgery [4] to radiotherapy [5]. These animal and human studies utilized focal irradiation at doses lower than would be expected to result in cell death. (Anatomically normal brain tissue has been found to have a higher tolerance to focal radiation than neoplastic brain tissue.)

Regis, et al. published results regarding an initial series of patients treated for epilepsy with Gamma Knife ${ }^{\circledast}$ (Elekta AB, Stockholm, Sweden) in 1994 (Regis et al 1994), and a second series in 2000 [6]. Treatment of refractory epilepsy has also been carried out with other radiosurgical instruments such as the CyberKnife ${ }^{\circledR}$ (Accuray Incorporated, Sunnyvale, California, USA) [7]. Romanelli and Anschel [8] reported on a series showing subnecrotic doses of radiation to neocortical foci improving seizure control. Uigg and Barbaro [9] have similarly reported therapeutic success with the use of radiation to irritable foci. Moreover, repeated studies demonstrate that radiosurgical "lesioning" of the trigeminal sensory root, in patients with trigeminal neuralgia $[1,10-15]$ can alleviate trigeminal pain while preserving the function of the parent nerve.

Our clinical experience suggests that the function of nervous tissue can be altered for an extended period of time, without frank cellular death of the involved region. The trigeminal nerve rhizotomy technique, with which we are most familiar, uses the CyberKnife to precisely target a six millimeter nerve segment with an approximate volume of $0.030-0.040 \mathrm{cc}$, using a marginal dose of $60 \mathrm{~Gy}$. Approximately $20 \%$ of patients leave the radiosurgical session with cessation of all trigeminal neuralgia. An additional $65 \%$ of cases obtain relief of pain over an average of five weeks. Seventeen percent of patients go on to develop ipsilateral facial numbness after a mean latency of seven months [16]. The ultimate durability of this effect is still under investigation, however, the therapeutic effects of radiosurgical neuromodulation treatment of trigeminal neuralgia appear to be generally sustained for several years. Given that the destructive effects of ionizing radiation requires months to occur, the immediate pain relief experienced by many patients is striking: Something other than nerve cell death could be responsible for the relief of pain.

\section{Putative mechanisms of action}

Ablation of normal brain tissue tends to occur at higher doses (relative to volume) than those which we believe to produce neuromodulation. In ablation, neurons and glia die. Fibrinoid necrosis, in tandem with thickening of blood vessel walls, narrowing of lumens and thrombosis may develop over times exceeding a year [17-18], and the site may liquefy [19]. At more moderate doses, radiation has been shown in the laboratory to reduce the electrophysiological reactivity of neurons. Laboratory rats given 90 cobalt gray equivalents (CGE) to brain targets by proton beam show electrophysiological changes, including a requirement for higher voltages to elicit post-synaptic potentials at three months following irradiation [20]. In a Gamma Knife rat epilepsy model, in rat brains exposed to $40 \mathrm{~Gy}$, spontaneous firing of neurons decreased by $55 \%$ as compared to controls, and this effect was sustained through several months of follow-up [21]. In this same study, at less than 50 Gy in histologically normal tissue, there was no evidence of necrosis: At 50-60 Gy, however, approximately $7 \%$ of the targeted tissue showed evidence of cell death. In guinea pig models, delivery of $50 \mathrm{~Gy}$ at a $20 \mathrm{~Gy} /$ minute rate produced 
reduced synaptic transmission efficiency, while 75 Gy additionally resulted in post-synaptic impairment.

At the slow radiation delivery rate of $5 \mathrm{~Gy} /$ minute, $100 \mathrm{~Gy}$ or more was required to cause synaptic impairment, while post-synaptic impairment was not dose-rate dependent [22]. The substrate of these changes is not known; however, ionizing radiation has also been shown to cause an inhibitory effect upon voltage-sensitive sodium channels in the rat brain [23]. This results in a state, in which the affected neurons remain chronically in a hyperpolarized state impervious to depolarization [24]. In summary, moderate-dose (non-necrotic/apoptotic) radiation delivered to non-neoplastic tissue serves to suppress neuronal activity "through mechanisms that change the functional characteristics of individual cells without killing those cells" [24]. These radiation-induced changes develop over a period of months [17], and may thereafter be permanent. Grossly evident changes to the nerve were not observed in six patients who underwent microvascular decompression eight to 46 months after having received Gamma Knife treatment of the trigeminal root entry zone [25].

Animal studies performed with radiation doses in boundary region between ablative and neuromodulation-compatible dose of 100Gy [26] have documented specific changes to blood vessels, glia, and interstitial space in the hours and months following irradiation. These documented changes provide possible alternative explanations for the observed neuromodulatory effects discussed in this paper. For example, edema becomes evident within hours of irradiation, and might disrupt connections between neurons, or between neurons and glia. Vascular endothelial hyperplasia, which becomes evident within 12 hours of irradiation, constrict microvascular supply to associated brain tissues, and could theoretically slow the activity of neurons which depend upon the adequate delivery of oxygen and nutrients, as well removal of metabolic waste products. Astrocyte proliferation, hyperplasia and hypertrophy ("reactive astrogliosis") occurs beginning within hours of irradiation, and could disrupt tripartite synapses, or otherwise alter neuronal activity via astrocyte signaling changes. Finally, damage to oligodendrocytes and Schwann cells is known to slow nerve conduction velocity.

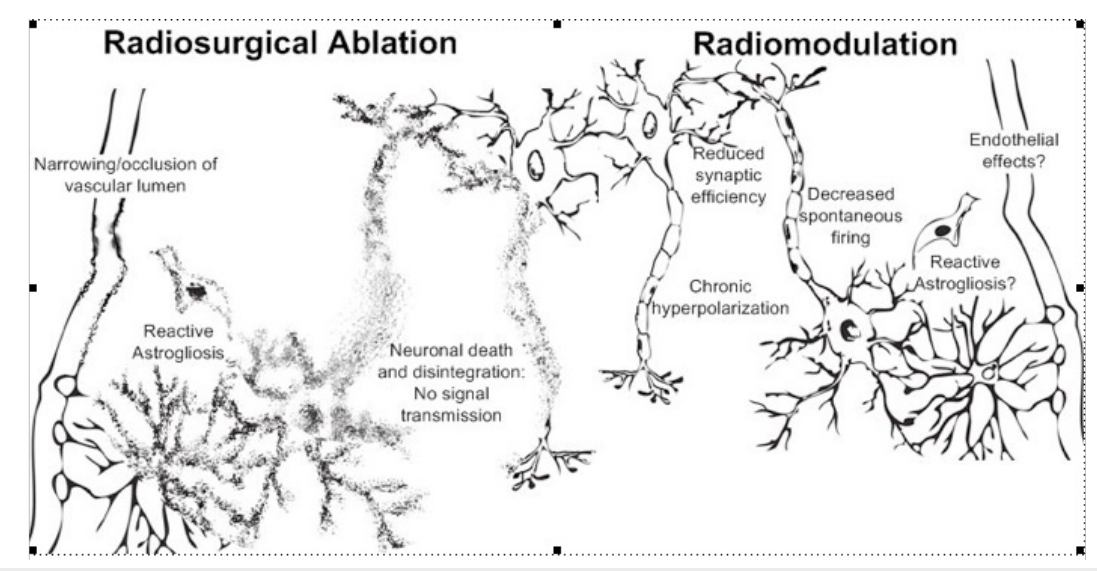

\section{FIGURE 1:}

Radiosurgical ablation is compared with radiation-based neuromodulation ("Radiomodulation"). Radiosurgical ablation (left) results in the death of brain tissue including neurons, glia and blood vessels, resulting in the loss of signal processing and transmission. By contrast, radiomodulation (right) chronically hyperpolarizes neurons, decreases their spontaneous firing rate, and reduces synaptic efficiency. Targeted tissue thereby continues to function at a slower, less reactive rate. (Original composite illustration by Schneider MB 2008. Neuron graphic element after Carlson 1992)

We propose that optimal pain relief may be achieved by altering neuronal behavior, without 
frank neuronal destruction. Radiation may thus place neurons in a state of ephaptic transmission as some have postulated in central and peripheral pain conditions [27-29], an effect that may also be akin to the mechanism of action of anticonvulsants in pain.

Of course, axonal degeneration and necrosis do occur, typically at doses of $80 \mathrm{~Gy}$ or more, and is indeed typically accompanied by both pain relief and numbness. However, it is suggested that this approach may be avoided in favor of the moderate-dose neuromodulation effects. It appears that, depending upon anatomical and volumetric particulars, doses in the 40 to $60 \mathrm{~Gy}$ range are most likely to yield modulation without ablation.

In practice, radiosurgical ablation and radiomodulation appear to co-exist on a continuum, and achieving reliable radiomodulation in the absence of ablation requires delicate balance. Producing radiomodulation in the effective absence of ablation will depend upon weighing several factors, primarily including the dose, the targeted tissue volume, and the intrinsic radiation susceptibility of the targeted tissue. The volume targeted is chiefly dictated by the spatial geometry of the brain tissue that one wishes to affect, and is therefore determined on a functional-anatomical basis.

Dose, by contrast, is being determined empirically, in the context of laboratory and clinical research, which specifically attempts to tease out the effects of radiomodulation. While animal research may be instructive, dose cannot be directly derived from such studies: laboratory animals may have an intrinsic tolerance to radiation/ susceptibility that differs from humans. Additionally, because humans have large brains compared with laboratory animals, a given volume of tissue contains a disproportionate amount of the critical cellular infrastructure required for tissue repair. Therefore, the dose/volume relationship for a given radiation effect in a small animal is likely to be disproportionally shifted toward a lower value, while the intrinsic susceptibility of their brain tissue may be greater or less than that of a human brain. Nor can the dose be directly derived from the clinical radiation oncology experience. By virtue of their rapid cell division (as compared with normal brain tissue), and often precarious blood supply, neoplasia is much more readily destroyed by relatively low doses of radiation. In fact, the classical radiobiology that underlies radiation therapy teaches us very little about radiomodulation.

To date, radiomodulation has been used principally for the sake of its local effect upon targeted tissue. In the case of epilepsy, radiomodulation is applied to the seizure focus and surrounding tissue, so as to limit the generation and propagation of seizure activity. In the case of trigeminal neuralgia, radiomodulation is used to decrease the irritability and reactivity of the nerve that registers excessive pain. However, potential uses of radiomodulation are much greater than such local-effect applications. Tuning of complex brain circuit dynamics-much as is done with implanted deep brain stimulation (DBS) electrodes- could be emulated noninvasively using radiation. By applying carefully dosed radiation to small, precisely selected volumes within brain circuits, we may be able to therapeutically alter the behavior of targeted brain circuits. Radioprotectant and radiosensitizer agents may prove useful for achieving such target/non-target differential effects.

Using contemporary functional imaging modalities, focal areas of metabolic disturbance may be identified within the context of clinical symptoms. By radiomodulating a hypermetabolic node in the circuit or associated white matter tracts, it may be possible to restore homeostasis in the treated circuit and treat clinical symptoms. This has particular implications for psychiatric and behavioral disorders: For example, by downwardly modulating activity within the subgenual cingulate (Cg25), we may be able to treat intractable depression, as previously demonstrated with DBS by Mayberg and Lozano [30]. 


\section{Cureus}

Radiation-based neuromodulation may prove to retain key differences, as well as similarities with other neuromodulation modalities, as shown in Table 1. Perhaps the most distinguishing characteristic of radiomodulation is the durable, possibly permanent nature of the treatment. This durability would theoretically be desirable provided that appropriate dosing and targeting strategies can be developed.

\begin{tabular}{|c|c|c|c|c|c|}
\hline & Invasive & Focal & Ability to Reach Deep Brain & Direction of Neuromodulation & $\begin{array}{l}\text { Duration } \\
\text { of Effect }\end{array}$ \\
\hline Radiomodulation & No & Yes & Yes & Down & $\begin{array}{l}\text { Likely } \\
\text { years to } \\
\text { permanent }\end{array}$ \\
\hline Electrical cortical stimulation & Yes & Yes & No & Up or down & $\begin{array}{l}\text { During } \\
\text { stimulation }\end{array}$ \\
\hline Deep brain stımulation & Yes & & Yes & Up or down & $\begin{array}{l}\text { During } \\
\text { stimulation }\end{array}$ \\
\hline stimulation & No & No & No & Up or down & $\begin{array}{l}\text { Months } \\
\text { after } \\
\text { stimulation }\end{array}$ \\
\hline $\begin{array}{l}\text { Iranscranial direct current } \\
\text { stimulation }\end{array}$ & No & No & No & Up or down & $\begin{array}{l}\text { Minutes } \\
\text { after } \\
\text { stimulation }\end{array}$ \\
\hline Optogenetic stimulation & Yes & Yes & Yes & Up or down & $\begin{array}{l}\text { During } \\
\text { stimulation }\end{array}$ \\
\hline
\end{tabular}

\section{TABLE 1: Major Neuromodulation Modalities Compared}

The key limitations of radiation-based neuromodulation are the nuances of determining correct targets, and doses that should be directed to those targets. Some small degree of necrosis may co-exist within predominantly viable irradiated tissue. The long time course required for posttreatment changes to reach homeostasis make dosing decisions even more complex. Like ablative procedures, radiomodulation effects appear to be substantially permanent, and therefore can't be iteratively tuned with the ease provided by electrical stimulation. Furthermore, some physicians and their patients might be adverse to radiation-based treatment because of concerns regarding sequelae of the exposure. Finally, radiation-based neuromodulation effect appears to be unidirectional: down-regulation of the target. While some evidence supports hyperactivity of neurons shortly after irradiation, the late/enduring effects appear to be suppressive only. This limits the application only to paradigms in which a hypermetabolic area of tissue requires downregulation.

\section{Conclusions}

When histologically normal brain tissue malfunctions, the frequent result is abnormal behavior, characteristic of psychiatric disease. Our evolving capabilities in functional brain 
imaging -- chiefly, PET, SPECT and fMRI -- increasingly reveal these regions of hypermetabolism and of hypometabolism that correlate with the psychiatric illness: Radiomodulation may offer a tool by which hypermetabolic foci may be downregulated. Theoretically, the chief advantage of radiomodulation over ablative radiosurgery is the preservation of relatively intact neural connectivity and avoidance of the adverse effects associated with destruction of that tissue: for example deafferentation pain. The potential key advantage of radiomodulation over implanted stimulation is the noninvasive nature of the approach that is devoid of most open surgical risks. Upon achievement of a successful treatment, the ultimate results would usually be permanent, and without concerns about battery changes, and/or replacing broken electrical leads. Theoretically, such an approach could translate into a safer, less costly and more accessible treatment for patient with functional brain disorders. Optimal parameters for stereotactic radiation-based neuromodulation will be revealed with further study, and as the capabilities of functional neuroimaging improve. It may be thereby possible to improve the behavior of functionally abnormal neural circuitry.

\section{Additional Information \\ Disclosures}

Conflicts of interest: In compliance with the ICMJE uniform disclosure form, all authors declare the following: Payment/services info: All authors have declared that no financial support was received from any organization for the submitted work. Financial relationships: John R. Adler declare(s) an alternate financial activity from Accuray, Inc. Shareholder. Bret Schneider declare(s) an alternate financial activity from Cervel Neurotech, Inc. Founder and Chief Medical Officer. Intellectual property info: Schneider MB, Borchers DJ, Adler JR. Radiosurgical Neuromodulation Devices, Systems and Methods for Treatment of Behavioral Disorders by External Application of Ionizing Radiation. US Patent No. 8,337,382 (2012). Schneider MB, Adler JR. Treatment of Anxiety Disorders by External Application of Ionizing Radiation. US Patent Application No. 61/651,470. . Other relationships: All authors have declared that there are no other relationships or activities that could appear to have influenced the submitted work.

\section{References}

1. Kondziolka D, Lunsford LD, Flickinger JC, Young RF, Vermeulen S, Duma CM, Jacques DB, Rand RW, Regis J, Peragut JC, Manera L, Epstein MH, Lindquist C: Stereotactic radiosurgery for trigeminal neuralgia: a multi-institutional study using the gamma unit. J Neurosurg . 1996, 84:940-45.

2. Regis J, Bartolomei F, Hayashi M, Chauvel P: Gamma Knife surgery, a neuromodulation therapy in epilepsy surgery. Acta Neurochir. 2002, 84:37-47.

3. Rossi GF, Scerrati M, Roselli R: Epileptogenic cerebral low-grade tumors: effect of interstitial stereotactic irradiation on seizures. Appl Neurophysiol . 1985, 48:127-132.

4. Heikkinen ER, Konnov B, Melnikov L, Yalynych N, Zubkov Yu N, Garmashov Yu A, Pak VA: Relief of epilepsy by radiosurgery of cerebral arteriovenous malformations . Stereotact Funct Neurosurg. 1989, 53:157-66.

5. Rogers LR, Morris HH, Lupica K: Effect of cranial irradiation on seizure frequency in adults with low-grade astrocytoma and medically intractable epilepsy. Neurology . 1993, 43:15991601.

6. Regis J, Bartolomei F, Rey M, Hayashi M, Chauvel P, Peragut JC: Gamma knife surgery for mesial temporal lobe epilepsy. J Neurosurg. 2000, 20:279-88.

7. House PA, Kim JH, Lanerolle ND, Barbaro NM: Radiosurgery in epilepsy-pathological considerations. Prog Neurol Surg. 2007, 20:279-88.

8. Romanelli P, Anschel DJ: Radiosurgery for epilepsy.. Lancet. 2006, 5:613-20.

9. Quigg M, Barbaro NM: Stereotactic radiosurgery for treatment of epilepsy. Arch Neurol. 2008, 65:177-83. 
10. Leksell L: Stereotaxic radiosurgery in trigeminal neuralgia . Acta Chir Scand . 1971, 137:31114.

11. Lim M, Cotrutz C, Romanelli P, Schaal D, Gibbs I, Chang SD, Adler JR: Stereotactic radiosurgery using CT cisternography and non-isocentric planning for the treatment of trigeminal neuralgia. Comput Aided Surg . 2006, 11:11-20.

12. Lim M, Villavicencio AT, Burneikiene S, Chang SD, Romanelli P, McNeely L, McIntyre M, Thramann JJ, Adler JR: CyberKnife radiosurgery for idiopathic trigeminal neuralgia . Neurosurg Focus. 2005, 18:5.

13. Lindquist C, Kihlstrom L, Hellstrand E: Functional neurosurgery-a future for the gamma knife?. Stereotact Funct Neurosurg . 1991, 57:72-81.

14. Tolliver JM, Pellmar TC: Ionizing radiation alters neuronal excitability in hippocampal slices of the guinea pig. . Radiation Res . 1987, 112:555-63.

15. Villavicencio AT, Lim M, Burneikiene S, Romanelli P, Adler JR, McNeely L, Chang SD, Fariselli L, McIntyre M, Bower R, Broggi G, Thramann JJ: Cyberknife radiosurgery for trigeminal neuralgia treatment: a preliminary multicenter experience. Neurosurgery. 2008, 62:647-655.

16. Adler JR, Bower R, Gupta G, Lim M, Efron A, Gibbs IC, Chang SD, Soltys SG: Non Nonisocentric radiosurgical rhizotomy for trigeminal neuralgia.. Neurosurgery. 2009, 64:84-90.

17. Yamaguchi N, Yamashima T, Yamashita J: A histological and flow cytometric study of dog brain endothelial cell injuries in delayed radiation necrosis. J Neurosurg . 1991, 74:625-32.

18. Yoshii Y, Phillips TL: Late vascular effects of whole brain X-irradiation in the mouse . Acta Neurochir . 1982, 64:87-102.

19. Yamamoto M, Jimbo M, Ide M, Lindquist C, Steiner L: Gamma Knife radiosurgery in cerebral arteriovenous malformations: post obliteration nidus changes observed on neurodiagnostic imaging. Stereotact Funct Neurosurg . 1995, 1:126-33.

20. Brisman JL, Cole AJ, Cosgrove GR, Thornton AF, Rabinov J, Bussiere M, Bradley-Moore M, Hedley-Whyte T, Chapman PH: Radiosurgery of the rat hippocampus: magnetic resonance imaging, neurophysiological, histological, and behavioral studies. Neurosurgery . 2003, 53:951-61.

21. Chen ZF, Kamiryo T, Henson SL, Yamamoto H, Bertram EH, Schottler F, Patel F, Steiner L, Prasad D, Kassell NF, Shareghis S, Lee KS: Anticonvulsant effects of gamma surgery in a model of chronic spontaneous limbic epilepsy in rats. J Neurosurg . 2001, 94:270-80.

22. Tolliver JM, Pellmar TC: Ionizing radiation alters neuronal excitability in hippocampal slices of the guinea pig. . Radiat Res. 1987, 112:555-63.

23. Mullin MJ, Hunt WA, Harris RA: Ionizing radiation alters the properties of sodium channels in rat brain synaptosomes. J Neurochem. 1986, 47:489-95.

24. Pellmar TC, Schauer DA, Zeman GH: Time- and dose-dependent changes in neuronal activity produced by X radiation in brain slices.. Radiation Res . 1990, 122:209-14.

25. Shetter AG, Zabramski JM, Speiser BL: Microvascular decompression after gamma knife surgery for trigeminal neuralgia: intraoperative findings and treatment outcomes. J Neurosurg . 2005, 102:259-61.

26. Yang T, Wu SL, Liang JC, Rao, ZR, Ju G: Time-dependent astroglial changes after gamma knife radiosurgery in the rat forebrain. Neurosurgery. 2000, 47:407-16.

27. Dudek FE, Yasumura T, Rash JE: 'Non-synaptic' mechanisms in seizures and epileptogenesis . Cell Biol Int . 1998, 22:793-805.

28. Machinis T, Fountas KN: Ephaptic transmission as an explanatory mechanism of radicular pain. South Med J . 2005, 98:673.

29. Willoughby JO: Mechanisms underlying partial (focal or lesional) epilepsy. J Clin Neurosci. 2000, 7:291-94.

30. Mayberg HS, Lozano AM, Voon V, McNeely HE, Seminowicz D, Hamani C, Schwalb JM, Kennedy SH: Deep brain stimulation for treatment-resistant depression . Neuron . 2005, 45:651-60. 